\title{
A RARE CAUSE OF HYPOGLYCEMIA IN A DIABETIC WOMAN: INSULINOMA
}

\section{Kenan Cadirci'1, Faruk Yıldız', Hakan Sevimli', Hakan Gözcü'1, Yasemin Kaya², Havva Keskinn ${ }^{3}$, Ayşe Carlioglu'}

\author{
1Department of Internal Medicine, Regional Training and Research Hospital, Erzurum, TURKEY \\ ${ }^{2}$ Department of Internal Medicine, Ordu University Faculty of Medicine, Ordu, TURKEY \\ ${ }^{3}$ Department of Internal Medicine, Göztepe Regional Training and Research Hospital, Istanbul, TURKEY
}

\section{Introduction}

insulinoma is a functional neuroendocrine tumor which is based on pancreatic $\beta$ cells and characterized with the autonomous insulin secretion. İnsulinoma is generally a rare benign tumor of the pancreas islet cell. Insulin provides clinical findings with the hypoglycemic symptoms about its excessive secretion. Its annual incidence is approximately four persons in one million. The typical clinical symptoms of insulinoma are repetitive hypoglycemia attacks consisting of symptoms such as perspiration, shivering, tachycardia, drowsiness, faint and coma. Insulinoma with coexisting diabetes is extremely rare condition, We aim to present a case with insulinoma conmomittant with type 2 diabetes mellitus.

\section{Case presantation}

A 65-year-old woman diagnosed with type 2 diabetes mellitus was admitted by our internal medicine clinic. She complained from perspiration and tremor when she was hungry. She was taken metformin $2000 \mathrm{mg} /$ day for 3 years. She had moist and sweaty skin in the examination. In the first laboratory analysis, plasma glucose was $62 \mathrm{mg} / \mathrm{dl}$ and HBA1c was $\% 4,4$. Plasma glucose maintained to decrease, although metformin treatment was quitted because of hypoglycemia. Plasma glucose during hypoglycemia was detected $47 \mathrm{mg} / \mathrm{dl}$, insulin $35,3 \mathrm{mIU} / \mathrm{ml}(2,4-$ 23,3) and $C$ peptide $3,51 \mathrm{ng} / \mathrm{ml}(0,9-4)$. Other biochemical tests, pituitary hormones and parathormone levels were normal. It was performed abdominal CT for the possibility of insulinoma. In the abdominal $\mathrm{CT}$, it was monitored a well-circumscribed mass, approximately in the size of $21 \times 20 \times 17 \mathrm{~mm}$ in pancreas caudal part. Distal pancreatectomy was performed in the patient. Pathological outcome of the patient was reported as insulinoma. There was no hypoglycemia in the patient after the operation

\section{Discussion}

Hypoglycemia attacks appearing in a patient with diabetes have always been associated with the treatment regimen used by patient. In patients having hypoglycemia, medicine and diet practice that might lead to this condition have been changed and the further examinations about the complaints of patients related to hypoglycemia have been the result of persistency and perpetuity of these complaints of patients.

In conclusion, insulinoma is a disease which is diffucult to diagnose because both clinical findings include neurological and psychiatric ones and hypoglycemic symptoms in a diabetic case is mostly associated with diabetes treatment. While hypoglycemia is researched in diabetic patients insulinoma has to be definitely taken into consideration and patients have to be examined in this respect.

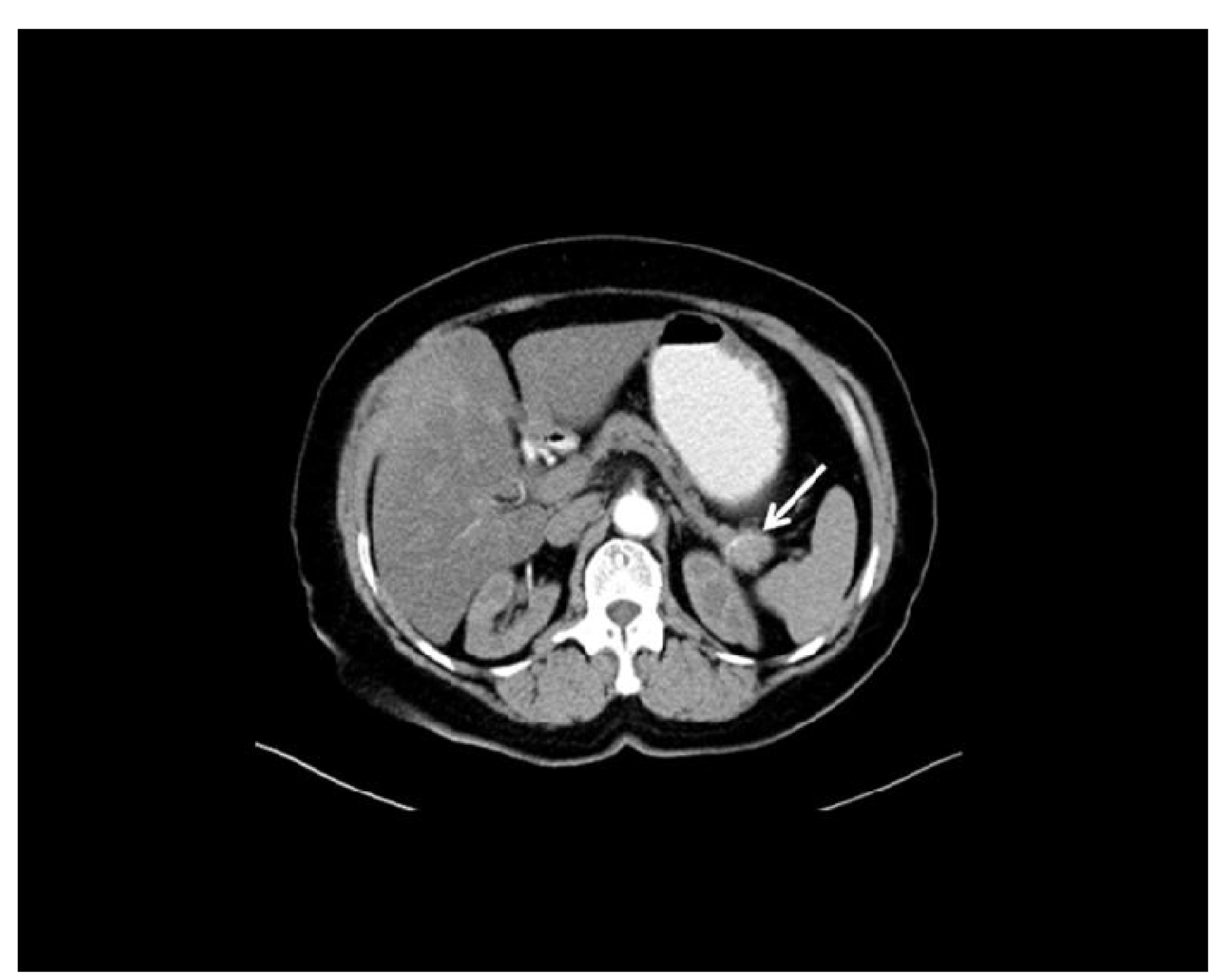

Figure 1: Axial contrast-enhanced image shows the solid lesion had apparent heterogenous contrast-enhenced pattern on arterial phase 